\title{
Oncologist 2
}

National Cancer Institute

\section{Source}

National Cancer Institute. Oncologist 2. NCI Thesaurus. Code C96612.

The second in a series of oncologists that are performing an assessment. 